\title{
The Bacteriostatic Activity of 2-Phenylethanol Derivatives Correlates with Membrane Binding Affinity
}

\author{
Isabel S. Kleinwächter ${ }^{1}$, Stefanie Pannwitt ${ }^{1}$, Alessia Centi ${ }^{2}$, Nadja Hellmann ${ }^{1}$, Eckhard Thines ${ }^{3}$, Tristan Bereau ${ }^{2,4}(\mathbb{D}$ \\ and Dirk Schneider 1,2,*(D) \\ 1 Department of Chemistry, Biochemistry, Johannes Gutenberg University Mainz, Hanns-Dieter-Hüsch-Weg 17, \\ 55128 Mainz, Germany; kisabels@uni-mainz.de (I.S.K.); Stefanie.Pannwitt@gmx.de (S.P.); \\ nhellmann@uni-mainz.de (N.H.) \\ 2 Max Planck Institute for Polymer Research, 55128 Mainz, Germany; centia@mpip-mainz.mpg.de (A.C.); \\ t.bereau@uva.nl (T.B.) \\ 3 Institute of Molecular Physiology, Johannes Gutenberg University, Hanns-Dieter-Hüsch-Weg 17, \\ 55128 Mainz, Germany; thines@uni-mainz.de \\ 4 Van 't Hoff Institute for Molecular Sciences and Informatics Institute, University of Amsterdam, \\ 1098 XH Amsterdam, The Netherlands \\ * Correspondence: Dirk.Schneider@uni-mainz.de; Tel.: +49-6131-39-25833; Fax: +49-6131-39-25348
}

check for updates

Citation: Kleinwächter, I.S.; Pannwitt, S.; Centi, A.; Hellmann, N.; Thines, E.; Bereau, T.; Schneider, D. The Bacteriostatic Activity of 2-Phenylethanol Derivatives Correlates with Membrane Binding Affinity. Membranes 2021, 11, 254. https://doi.org/10.3390/membranes 11040254

Academic Editor: Luis Octavio Regasini

Received: 9 March 2021

Accepted: 26 March 2021

Published: 31 March 2021

Publisher's Note: MDPI stays neutral with regard to jurisdictional claims in published maps and institutional affiliations.

Copyright: (c) 2021 by the authors. Licensee MDPI, Basel, Switzerland. This article is an open access article distributed under the terms and conditions of the Creative Commons Attribution (CC BY) license (https:// creativecommons.org/licenses/by/ $4.0 /)$.

\begin{abstract}
The hydrophobic tails of aliphatic primary alcohols do insert into the hydrophobic core of a lipid bilayer. Thereby, they disrupt hydrophobic interactions between the lipid molecules, resulting in a decreased lipid order, i.e., an increased membrane fluidity. While aromatic alcohols, such as 2-phenylethanol, also insert into lipid bilayers and disturb the membrane organization, the impact of aromatic alcohols on the structure of biological membranes, as well as the potential physiological implication of membrane incorporation has only been studied to a limited extent. Although diverse targets are discussed to be causing the bacteriostatic and bactericidal activity of 2-phenylethanol, it is clear that 2-phenylethanol severely affects the structure of biomembranes, which has been linked to its bacteriostatic activity. Yet, in fungi some 2-phenylethanol derivatives are also produced, some of which appear to also have bacteriostatic activities. We showed that the 2-phenylethanol derivatives phenylacetic acid, phenyllactic acid, and methyl phenylacetate, but not Tyrosol, were fully incorporated into model membranes and affected the membrane organization. Furthermore, we observed that the propensity of the herein-analyzed molecules to partition into biomembranes positively correlated with their respective bacteriostatic activity, which clearly linked the bacteriotoxic activity of the substances to biomembranes.
\end{abstract}

Keywords: 2-phenylethanol; phenylacetic acid; phenyllactic acid; methyl phenylacetate; Tyrosol; biomembranes; membrane interaction; bacteriotoxic

\section{Introduction}

Due to their amphipathic properties, alcohols affect numerous biological processes, many of which are related to cellular membranes. The hydrophobic tails of alcohols insert into the hydrophobic core region of a lipid bilayer and disrupt hydrophobic interactions between the lipid molecules, resulting in a decreased lipid order, i.e., an increased membrane fluidity [1,2]. The exact impact of alcohol on the structure of a lipid bilayer depends on the length and overall hydrophobicity of the alcohol alkyl chain, and it is predicted that the effect of alcohols on membranes increases with increasing alkyl chain lengths [3]. Thus far, the impact of alcohols on biomembranes has been studied to a great extent using, aliphatic primary alcohols, albeit aromatic alcohols, such as 2-phenylethanol (2-PEtOH), also insert into lipid bilayers and disturb the membrane organization [4].

2-PEtOH, a compound also known as phenylethyl alcohol or benzylcarbiol, is a colorless liquid with a rose-like odor. 2-PEtOH occurs widely in nature and is-besides in 
rose extracts - a major component in a variety of plant extracts from carnations, hyacinths, jasminum, geranium species, and others [5]. 2-PEtOH has been shown to affect cell proliferation in bacteria, yeast, plants, fungi, and mammalian cells, albeit its exact mode of action is still under debate [6-9]. Due to its bactericidal effect, 2-PEtOH is frequently used in concentrations of up to $100 \mathrm{mM}$ to protect pharmaceuticals, cosmetics, and other personal care products from spoilage. However, 2-PEtOH is already bacteriostatic at vastly lower concentrations, starting at concentrations as low as $8 \mathrm{mM}$ with explicit effects at 12-16 $\mathrm{mM}$ [7].

2-PEtOH appears to affect DNA, RNA, and protein synthesis in bacteria [10-12]. Additionally, it has been suggested that the bactericidal activity of 2-PEtOH in fact depends on its conversion into phenylacetaldehyde, which is way more toxic to bacteria than 2-PEtOH [12]. Yet, while diverse targets are discussed to be causing the bacteriostatic activity of 2-PEtOH, it is clear that 2-PEtOH partitions into bacterial membranes and severely affects the structure of biomembranes $[4,7,13]$. As observed with other alcohols, the interaction of 2-PEtOH with the model as well as with biological membranes results in a drastic change of the lipid acyl-chain order [14-16]. This 2-PEtOH-induced change in the lipid order significantly affects the dimerization of transmembrane helices in the model, as well as in cellular membranes [14]. Thus, 2-PEtOH-induced lipid disordering might crucially affect the structure of transmembrane proteins in general, and this effect on the structure of biological membranes might be the first and ultimate line of the 2-PEtOH bacteriostatic activity.

Further, 2-PEtOH is also produced by some fungi, which can significantly retard their growth and development [6,9]. Yet, fungi also produce some 2-PEtOH-derivatives, such as Tyrosol, phenyllactic acid, and phenylacetic acid (Figure 1), some of which appear to also have bacteriostatic activities. Already decades ago, a correlation between the bacteriostatic activity of phenyl-substituted alcohols (other than analyzed here) and their partitioning between an aqueous phase and an organic layer was described, and it was suggested that the compounds acted on cellular membranes [13]. Thus, it is reasonable to assume that the 2-PEtOH derivatives also act on cellular membranes and affect cell viability.

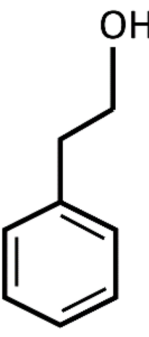

A

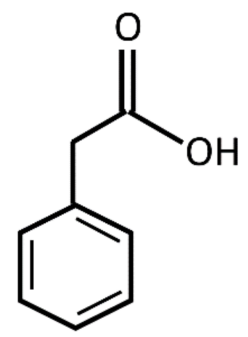

B

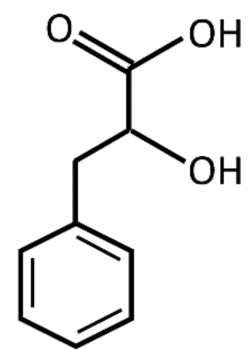

D

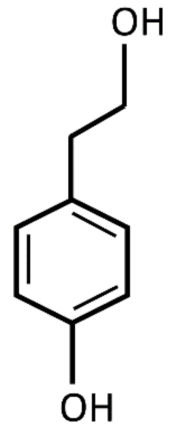

C

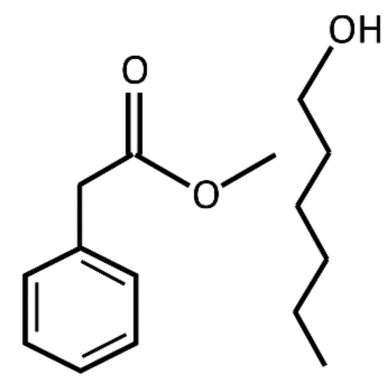

$\mathbf{E}$

Figure 1. Chemical structures of 2-phenylethanol (2-PEtOH) and derivatives. 2-phenylethanol (A), phenylacetic acid (B), phenyllactic acid (C), Tyrosol (D), methyl phenylacetate (E), and 1-hexanol (F). The structures were drawn with ChemSketch V5.

Similar to 2-PEtOH, phenyllactic acid, the metabolite of phenylethylamine that occurs in the phenylalanine metabolism [17-19], also appears to have antimicrobial properties, targeting fungi and bacteria [14,15,20-22]. Just as for 2-PEtOH, also for phenyllactic acid, diverse modes of actions are discussed, and the compound appears to affect the integrity of the bacterial cell wall [14,20], and/or it might intercalate into the DNA and hinder DNA replication [23].

Yet, just as 2-PEtOH, it has been suggested that phenylacetic acid does also act at the cell membrane, albeit not knowing the mode of action [17]. Clearly, phenylacetic 
acid can passively cross liposomal membranes in vitro [24], and a correlation between the membrane partition coefficients of some of its para-substituents and their bacteriostatic properties is described [25], and phenyllactic acid potentially makes the outer membrane of Escherichia coli more permeable, without disrupting it [23]. In contrast to 2-PEtOH and phenylacetic acid, membrane interaction of methyl phenylacetate, the methyl ester of phenylacetic acid, which is produced by several plants, has not been analyzed yet.

Tyrosol belongs to the most widely distributed compounds in plants [16]. It is the major phenolic compound found in olive oil, red wine and white wine [26,27].

While membrane interaction of 2-PEtOH has been studied to some extent and the bacteriostatic activity of 2-PEtOH has been linked to its membrane activity, the interaction of 2-PEtOH derivatives with model and biomembranes has only marginally been studied, if at all. Given that most compounds have an amphipathic nature, membrane interaction is expected, and it is well possible that membrane interactions affect bacterial homeostasis. In the present study, we showed that the 2-PEtOH derivatives phenylacetic acid, phenyllactic acid, and methyl phenylacetate (Figure 1) were incorporated into the model membranes and affected the membrane structure. The higher the overall hydrophobicity of a 2-PEtOH derivative, the higher its fluidizing impact on a membrane. Furthermore, we observed a positive correlation between membrane partitioning and the bacteriostaticity of the here analyzed 2-PEtOH derivatives.

\section{Materials and Methods}

\subsection{Lipids and Chemicals}

E. coli total lipid extract (EPL) was purchased from Avanti Polar Lipids (Alabaster, AL, USA). Laurdan (6-dodecanoyl-2-dimethylamino) was purchased from Sigma-Aldrich (Munich, Germany).

2-PEtOH, phenylacetic acid, phenyllactic acid, Tyrosol, 1-hexanol, and methyl phenylacetate were all purchased from Sigma-Aldrich (Munich, Germany). All structures were drawn with the program ChemSketch V5 (Freeware from ACD/Labs, Toronto, Ontario, Canada). The partition coefficient ( $\log \mathrm{P}$ value) was calculated using Molinspiration v2016.10 (www.molinspiration.com, accessed on 21 June 2018.).

It can be expected that the effect of a given compound on a membrane correlates with its tendency to incorporate into the membrane, represented by the corresponding partitioning coefficient $P$. This type of correlation is probed as [28]

$$
\log \frac{1}{\mathrm{C}}=\mathrm{a} \times \log \mathrm{P}+\mathrm{b}
$$

if only $\log P$ is considered as the predictor for the activity of the substance, with $a$ and $b$ being constants and $C$ the concentration relevant for the effect to be tested, here: Minimal inhibitory concentration 50 (MIC50; see [28] for a recent discussion of the approach).

\subsection{Laurdan Fluorescence Spectroscopy and Generalized Polarization (GP) Values}

For liposome preparation, $25 \mu \mathrm{L}$ EPL (10 mM in chloroform and methanol, 2:1) was mixed with laurdan (dissolved in methanol) in a 500:1 molar ratio. The solvents were removed under a nitrogen stream, and the remaining traces of the solvent were removed by overnight vacuum desiccation. The next day, $250 \mu \mathrm{L}$ of the substances dissolved in $10 \mathrm{mM}$ 4-(2-hydroxyethyl)-1-piperazineethanesulfonic acid (HEPES)-buffer (pH 7.4, $150 \mathrm{mM} \mathrm{NaCl}$ ) at the desired concentrations were added and the lipid film was rehydrated, resulting in a solution with $1 \mathrm{mM}$ lipid.

The mixture was vortexed and subsequently incubated for 30 minutes at $37^{\circ} \mathrm{C}$ and $1000 \mathrm{rpm}$ on a Thermoblock mixer comfort from Eppendorf. To prepare large unilamellar liposomes (LUVs), five freeze-thaw cycles were performed. The liposomes were again incubated for 30 minutes at $37^{\circ} \mathrm{C}$ and $1000 \mathrm{rpm}$ on a Thermoblock mixer comfort from Eppendorf (Hamburg, Germany). Laurdan spectra were recorded at $25^{\circ} \mathrm{C}$ using a FluoroMax-4 fluorescence spectrometer (Horiba (Bensheim, Germany)). The excitation and 
emission slits were set to $2 \mathrm{~nm}$, and the spectra were recorded between 400 and $550 \mathrm{~nm}$ with excitation at $350 \mathrm{~nm}$. Each tested substance was measured at least three times at each concentration using freshly prepared liposomes.

The generalized polarization (GP) values were calculated from the fluorescence emission spectra using the following equation [29].

$$
\mathrm{GP}=\frac{\mathrm{I}_{440}-\mathrm{I}_{490}}{\mathrm{I}_{440}+\mathrm{I}_{490}}
$$

$\mathrm{I}_{440}$ and $\mathrm{I}_{490}$ are the emission intensities at 440 and $490 \mathrm{~nm}$ [29]. The range of concentrations employed was limited by the solubility of the tested substances in an aqueous buffer. Tyrosol and 2-phenylethanol were measured up to $100 \mathrm{mM}$, phenylacetic acid and phenyllactic acid up to $80 \mathrm{mM}$, 1-hexanol up to $70 \mathrm{mM}$, and methyl phenylacetate up to $15 \mathrm{mM}$.

\subsection{Growth Assay and Determination of Minimal Inhibitory Concentrations $50\left(M C_{50}\right)$}

Escherichia coli strain MC4100 was grown in a terrific broth (TB)-medium buffered with $10 \% \mathrm{~K}_{2} \mathrm{HPO}_{4} / \mathrm{KH}_{2} \mathrm{PO}_{4}(0.17 \mathrm{M} / 0.72 \mathrm{M}) .20 \mathrm{~mL}$ TB medium with 1:1000 streptomycin (50 $\mathrm{mg} / \mathrm{mL}$ ) was prepared, and the tested substance was dissolved in the medium at the given concentration. From an overnight culture, E. coli MC4100 was diluted in fresh medium to an $\mathrm{OD}_{600}$ of 0.2 . The cultures were incubated at $37^{\circ} \mathrm{C}$ and $200 \mathrm{rpm}$ for four hours, the $\mathrm{OD}_{600}$ of a 5 fold diluted sample was measured, and the real value was calculated. The highest tested concentration was defined by the solubility of the tested substances in TB-medium or was the concentration where the E. coli were not able to grow anymore. A dose-response curve was fit to the data with a modified Hill equation using OriginPro 8.6 (Northampton, MA, USA), [30], with the concentration of the substance $x$ and the parameter e reflecting the MIC50 for each tested substance (Figure 4).

$$
y=c+\frac{d-c}{1+\left(\frac{x}{e}\right)^{b}}
$$

In order to get an idea about the concentration of the substance incorporated into the E. coli membrane, we calculated the overall surface area presented by the bacteria and, based on the partition coefficient, calculated the concentration of the lipids required to obtain the corresponding area $/ \mathrm{ml}$ as liposomes. According to [31], an OD of 0.2 corresponds to about $2 \times 10^{8} \mathrm{E}$. coli cells $/ \mathrm{ml}$. The surface area of an E. coli cell is about $3 \mu^{2}{ }^{2}$ [32], corresponding to about $4.2 \times 10^{6}$ lipid molecules, assuming $0.7 \mathrm{~nm}^{2} /$ lipid [33]. Thus, the concentration of the lipids necessary to create the corresponding area of a lipid bilayer is about $3 \mu \mathrm{M}$.

\subsection{Computer Simulations}

We followed previously established simulation protocols that were described in detail elsewhere [34,35]. Coarse-grained simulations were performed using Gromacs 4.6 [36] and the Martini force field [37]. Small molecules were parametrized using the auto-martini scheme [38] and inserted into a symmetric di-linoleoyl-phosphatidyl-choline (DLiPC) bilayer consisting of 64 lipids per leaflet and solvated in water. We ran simulations in the NPT ensemble at $300 \mathrm{~K}$ and 1 bar. Each simulation included a sequence of minimization, heat-up, and equilibration runs prior to the production one, the latter being simulated for $10^{5} \tau$ using a time step of $\delta t=0.02 \tau$, where $\tau(1 \mathrm{ps})$ refers to the model's natural unit of time.

\section{Results and Discussion}

The impact of 2-PEtOH on the structure and the stability of the model, as well as biological membranes, were studied in the past [6-8,14-16]. Nevertheless, plants, some fungi, as well as some bacteria produce and secrete the 2-PEtOH derivatives phenylacetic acid, phenyllactic acid, and Tyrosol (Figure 1). While it was suggested that phenyllactic 
acid permeabilizes the outer membrane of bacteria (by a yet unknown mechanism) [23], the membrane activity of the 2-PEtOH derivatives is largely unexplored. All molecules are amphiphilic and have a polar region with hydroxyl or carboxyl groups and a non-polar phenyl ring. An exception is Tyrosol, which has an extra hydroxyl group at the phenyl ring that renders the molecule non-amphiphilic [16]. Furthermore, in the present study, we additionally analyzed methyl phenylacetate, the methyl ester of phenylacetic acid produced in some plants, as it allows separating effects of the polar group from effects potentially caused by the negative charge of the carboxylate group. Furthermore, 1-hexanol, whose membrane interaction is well studied [1,2], was used as a non-aromatic control.

\subsection{Membrane Partitioning and the Impact of 2-PEtOH Derivatives on the Membrane Structure}

To estimate the membrane-binding affinity of the here-analyzed substances, we first calculated $\log \mathrm{P}$ values (Table 1), which provide information as to the partitioning of the substances between water and octanol (which is typically used as a mimic of the hydrophobic membrane core). This calculation is based on the hydrophobicity and polarity of a substance, and the less hydrophobic a molecule, the lower the logP value [39].

Table 1. $\log \mathrm{P}$ and MIC50 values of 2-PEtOH and derivatives.

\begin{tabular}{ccc}
\hline Substance & $\log \mathbf{P}$ & $\mathbf{M I C}_{\mathbf{5 0}}$ \\
\hline phenyllactic acid & 0.72 & 44.97 \\
Tyrosol & 1.00 & 29.74 \\
phenylacetic acid & 1.36 & 20.28 \\
2-phenylethanol & 1.49 & 14.89 \\
methyl phenylacetate & 1.98 & 6.30 \\
1-hexanol & 2.13 & 7.05 \\
\hline
\end{tabular}

The logarithm of the partition coefficient $(\log P)$ values of the substances, which provide information as to membrane partitioning of a molecule, were calculated with the online Molinspiration software v2016.10. The higher the value, the more hydrophobic the molecule and the higher will be the fraction of the membrane incorporated substance. The minimal inhibitory (MIC50) value provides information as to the bacteriostatic potential of a molecule (compare Figure 4). The higher this value, the less bacteriostatic a substance.

Phenyllactic acid has the lowest $\log \mathrm{P}$ value and, thus, is the least hydrophobic molecule analyzed here, and 1-hexanol is the most hydrophobic molecule with the highest $\log \mathrm{P}$ value of our studied substances.

Based on the definition of the $\log \mathrm{P}$, it is evident that a substance with a negative $\log \mathrm{P}$ has a higher affinity to the aqueous phase, and a positive $\log \mathrm{P}$ denotes a higher concentration in the lipid phase. Thus, based on this analysis, we expected all our tested substances to incorporate into the membrane (the lipid phase) as all the calculated values are positive [40]. Indeed, computer simulations clearly indicated that all substances incorporated around the lipid head groups (Figure 2). The ring lies deeper in the membrane than the side chain for all substances except Tyrosol. In fact, the angle distribution shown below (Figure 2) indicated that Tyrosol did not intercalate into a membrane but rather bound parallel on a membrane surface, in line with previous assumptions [16,41]. The angle between the membrane bilayer normal and the orientation of Tyrosol was just about $90^{\circ}$, while all other compounds showed much larger angles (Figure $2 \mathrm{~F}$ ).

Thus, all 2-PEtOH derivatives intercalated into a lipid monolayer, except Tyrosol, where direct interactions with the lipid acyl chains were not expected.

As membrane integration and membrane activity of 2-PEtOH had been demonstrated in the past, we next determined the impact of 2-PEtOH derivatives on the structure of model membranes via laurdan fluorescence spectroscopy $[1,2,8,9,14,17,20]$. Laurdan is a fluorescent dye that incorporates in lipid bilayers. Changes in the laurdan fluorescence emission spectrum reflect changes in the dye's ultimate environment, e.g., caused by altered lipid packing. To quantify the impact of a molecule on the structure of a lipid bilayer, the generalized polarization (GP) value was calculated [42]. A high GP value $(\approx+0.4)$ is characteristic for a rigid lipid bilayer with densely packed lipid molecules, i.e., the membrane gel state, whereas a low GP value $(\approx-0.2)$ is characteristic for less 
densely packed lipid bilayers, i.e., the fluid membrane state. As these values are largely independent of the lipid head groups and acyl chains, changes in the GP value can provide information about changes in the lipid order upon the addition of substances [43].

To this end, unilamellar liposomes were prepared from E. coli lipids containing $2 \mu \mathrm{M}$ Laurdan as well as increasing concentrations of the substances analyzed here. Changes in lipid packing were determined via laurdan fluorescence spectroscopy and illustrated as changes in the GP values (Figure 3). For further details, see Materials and Methods.
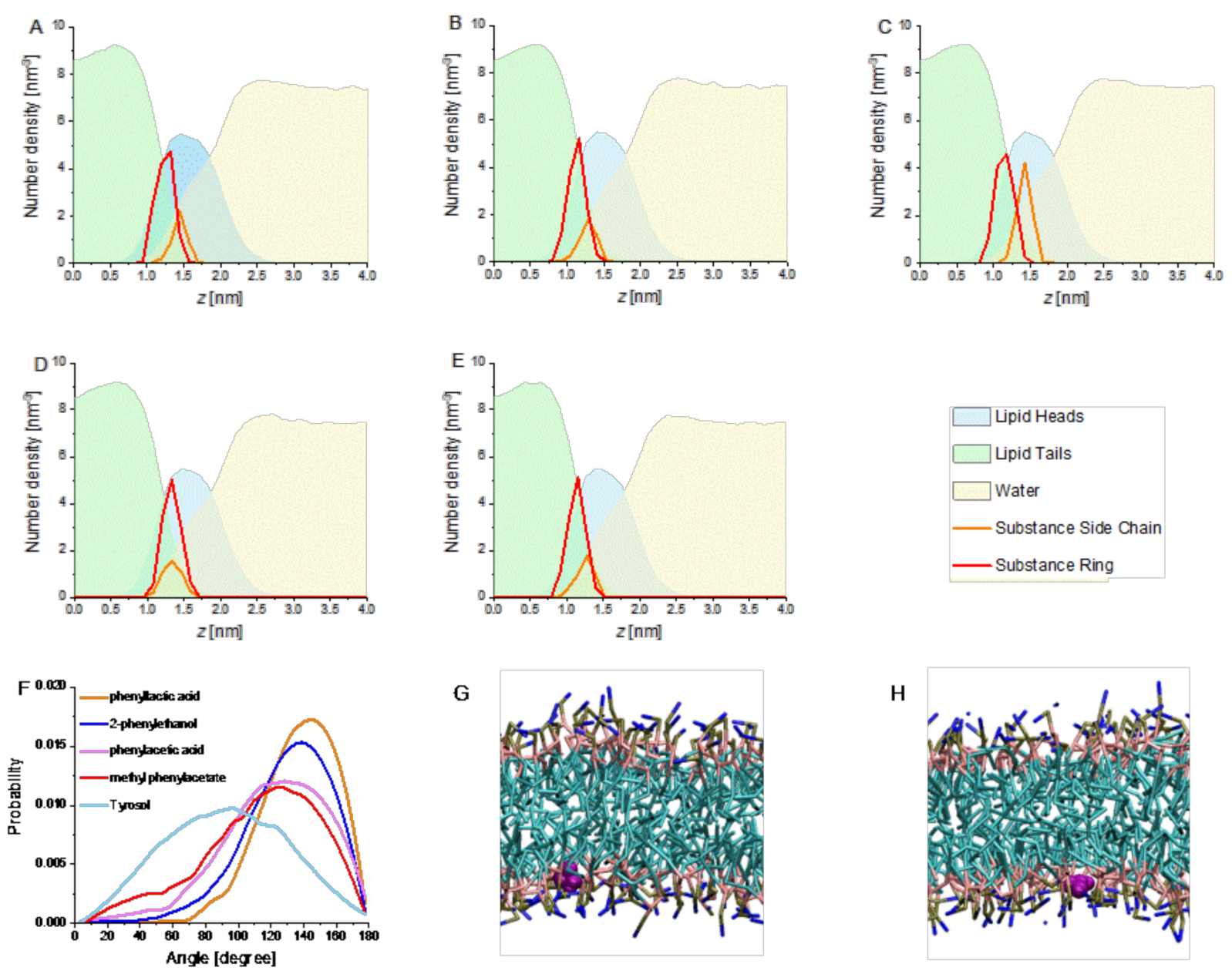

Figure 2. Number-density profiles, compound orientation relative to the membrane normal and simulation snapshots. (A-E) The number-density profiles report the molar fraction of different chemical groups in the simulation box, perpendicular to the bilayer. (A) 2-PEtOH, (B) phenylacetic acid, (C) phenyllactic acid, (D) Tyrosol, and (E) methyl phenylacetate. All substances have shifts between the side chain and ring, except Tyrosol. Molar fractions of the solutes have been multiplied by 50 for clarity. All substances spontaneously insert close to the lipid head groups. (F) The angle between membrane normal and compound orientation (defined from side chain to aromatic ring) shows large values for methyl phenylacetate, phenylacetic acid, 2-PEtOH, and phenyllactic acid, indicative of their intercalation in the membrane. Smaller values are reported for Tyrosol, indicating its binding parallel to the membrane surface. $(\mathbf{G}, \mathbf{H})$ Representative simulation snapshots of 2-PEtOH and Tyrosol (purple) inserted in the headgroup region of the phospholipid membrane. Water is not shown for clarity.

2-PEtOH and 1-hexanol are well known to increase membrane fluidity $[1,2,8]$. In line with this, the GP values measured here with increasing 2-PEtOH and 1-hexanol concentrations, respectively, are constantly decreasing (Figure 3), indicating a membrane fluidizing effect of all substances. For the maximal tested concentrations of the two substances, $70 \mathrm{mM}$ for 1-hexanol and $100 \mathrm{mM}$ for 2-PEtOH, the GP value is around -0.2. This value is characteristic of a bilayer in the fluid (liquid crystalline) phase [42,43]. Here, 2-PEtOH acts 
like 1-hexanol, although the impact of 1-hexanol on the lipid acyl chain order was more pronounced already at lower concentrations.

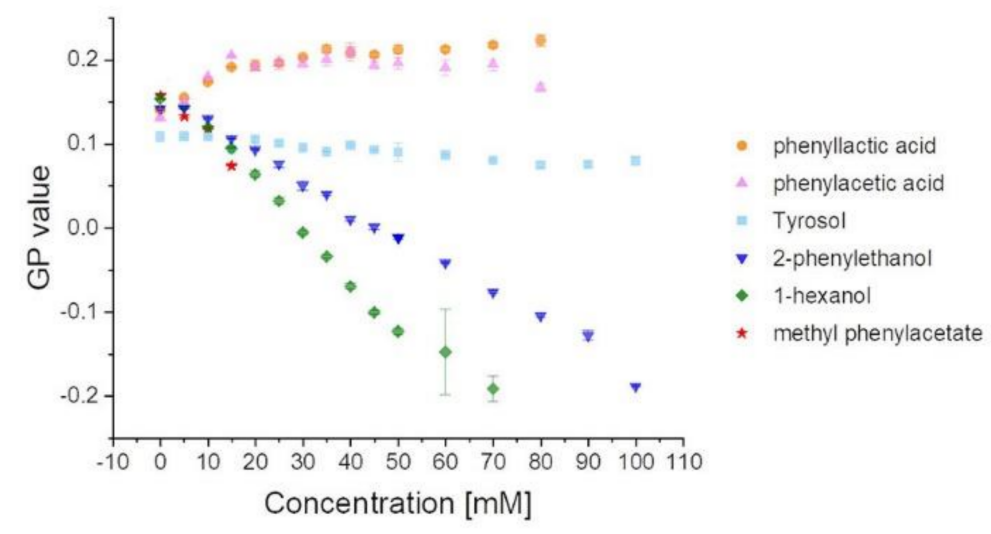

Figure 3. 2-PEtOH and derivatives affect the structure of the model membranes. GP values determined at increasing substance concentrations are shown. The values indicate a fluidizing effect for the more hydrophobic substances 1-hexanol, 2-PEtOH, and methyl phenylacetate. Tyrosol seems to be largely ineffective, while phenyllactic acid and phenylacetic acid seem to have a slight ordering effect.

Yet, even though Tyrosol binds solely to membrane surfaces, an impact on the lipid order might be expected. However, we did not see any change of the GP values with increasing Tyrosol concentrations, and thus, apparently, surface adhesion of Tyrosol does not (significantly) affect the membrane structure.

Further, for phenylacetic acid and phenyllactic acid, it was suggested that they could incorporate into membranes $[14,17,20,24]$, which is in line with the calculated logP values (Table 1). Yet, in contrast to 2-PEtOH, the addition of both phenyllactic acid as well as phenylacetic acid to E. coli lipid membranes did result in increasing GP values, which remained constant at concentrations larger than $15 \mathrm{mM}$. Thus, phenylacetic acid and phenyllactic acid both appeared to increase rather than decrease the membrane lipid order creating a more rigid membrane. Nevertheless, the membrane ordering effect was much lower than the disordering effect of 2-PEtOH or 1-hexanol.

To estimate whether the reverse impact of the two acids, compared to 2-PEtOH, might be caused by the negative charge, we additionally analyzed the impact of the methyl ester of phenylacetic acid, methyl phenylacetate, on the membrane structure. The addition of methyl phenylacetate to the model membranes resulted in decreasing GP values, as observed with 2-PEtOH or 1-hexanol. Consequently, membrane incorporation of methyl phenylacetate increased the membrane fluidity, and thus masking the negative charge of phenylacetic acid seemed to have a significant impact on the membrane activity (as further discussed below).

\subsection{2-PEtOH and Derivatives Are Bacteriostatic}

For all substances, except for Tyrosol, we showed that membrane binding had an impact on the membrane structure. Next, to test whether this membrane activity correlates with a potential bacteriostatic activity of the substances, the impact of 2-PEtOH, phenylacetic acid, phenyllactic acid, methyl phenylacetate, Tyrosol, and 1-hexanol on the growth of the bacterium E. coli was tested. For 2-PEtOH, it was already shown that it decreases bacterial growth starting at concentrations as low as $8 \mathrm{mM}$ with explicit effects at $12-16 \mathrm{mM}$ [7]. We followed bacterial growth in presence of increasing substance concentrations to calculate the (non-lethal) amount of substance that inhibits $50 \%$ bacterial growth (Figure 4). 

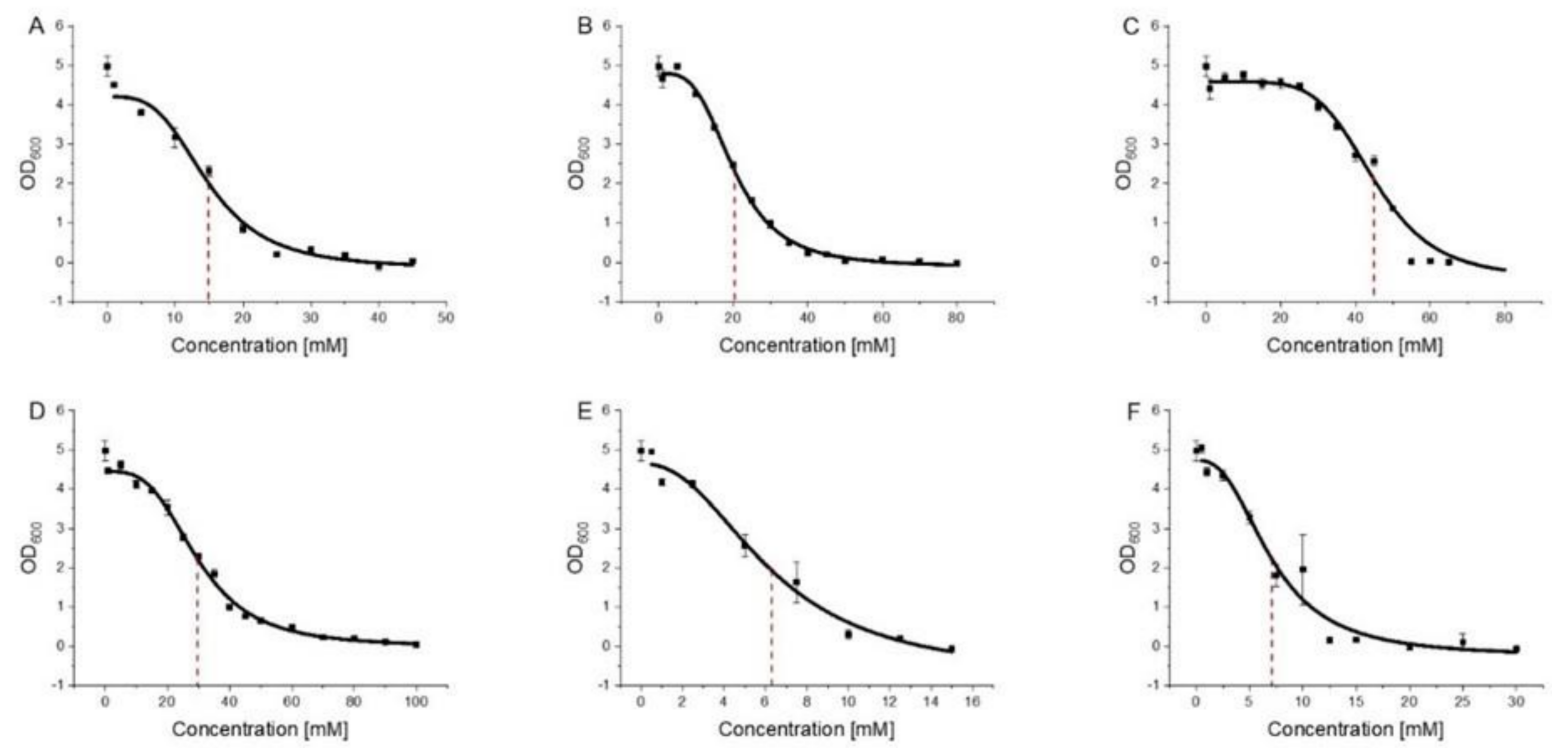

Figure 4. Determination of MIC50 values. The $\mathrm{OD}_{600}$ was plotted against the substance concentration and a dose-response fit was performed for (A) 2-PEtOH, (B) phenylacetic acid, (C) phenyllactic acid, (D) Tyrosol, (E) methyl phenylacetate, and (F) 1-hexanol $(\mathrm{n}=3, \pm \mathrm{SD})$. The corresponding MIC50 values are given in Table 1.

This minimal inhibitory (MIC50) value is a measure of the antimicrobial activity of compounds [44].

In excellent agreement with literature values, we here observed a clear effect of 2PEtOH on E. coli growth with an MIC50 value of $15 \mathrm{mM}$ [5-9]. As for phenylacetic acid, we likewise observed a bacteriostatic effect with an MIC50 value of $\sim 20 \mathrm{mM}$. However, when we masked the negative charge and analyzed the methyl phenylacetate instead, the MIC50 value was lowered to $~ 6.3 \mathrm{mM}$, a value lower than 2-PEtOH and in the same range as observed with 1-hexanol. This showed that masking the negative charge not only considerably affected the membrane activity of (methyl) phenylacetate (Figure 3) but also significantly enhanced its bacteriostatic efficiency. Surprisingly, while Tyrosol did not integrate into and affect the structure of biomembranes but rather lies flat on membrane surfaces (Figure 2H), it still affected the E. coli growth with an MIC50 value of $\sim 30 \mathrm{mM}[16,40]$. The naturally produced 2-PEtOH derivative phenyllactic acid was least active with an MIC50 as high as $\sim 45 \mathrm{mM}$. The determined MIC50 values are summarized in Table 1 for each of the tested substances.

\subsection{Hydrophobicity, Membrane Fluidity, and Bacterial Growth Correlate}

The here-analyzed molecules with the highest $\log \mathrm{P}$ values decreased the membrane order with increasing concentration, whereas phenylacetic acid and phenyllactic acid, which both have a low $\log \mathrm{P}$ value, showed increasing GP values with increasing concentration. Thus, the higher the overall hydrophobicity of a molecule, the higher its fluidizing impact on a membrane. Nevertheless, as all molecules, except the control 1-hexanol as well as Tyrosol, had a methylene benzene group, the chemistry of the substituents was evidently important for the membrane activity of 2-PEtOH derivatives. In contrast to 2-PEtOH, phenylacetic acid and phenyllactic acid did not decrease but slightly increased the order of a lipid bilayer. Yet, when masking the negative charge via the formation of a methyl ester, methyl phenylacetate showed an even increased membrane fluidizing activity compared to 2-PEtOH. Thus, the incorporation of the hydrophobic methylene benzene group into the hydrophobic membrane core region, as well as (polar) interactions within the lipid head group region, likely together affect the membrane activity of 2-PEtOH derivatives (as well as of other substances). This appears to be nicely reflected by the calculated overall hydrophobicity, i.e., the calculated $\log P$ values. 
Based on several subsequent studies, the bacteriostatic activity of 2-PEtOH was linked to biological membranes, albeit the exact mode of action is still unclear, and other target structures were also discussed [4,7-9]. Yet, the calculated $\log P$ values nicely correlated with the determined MIC50 values (Figure 5), and with an increasing $\log$ P value, the MIC50 decreased. In fact, when we plot the logarithm of the MIC50 values determined for the 2$\mathrm{PEtOH}$ derivatives against the calculated $\log \mathrm{P}$ values, we obtained a linear correlation with an $\mathrm{r}^{2}$ value of 0.987 (Figure 5). Thus, the hydrophobicity of the molecules, i.e., their calculated propensity to partition into biomembranes, correlated with the bacteriostatic activity, which indicated that the partition coefficient significantly determined the biological activity of the substances and links the bacterotoxic activity of the substances to biomembranes.

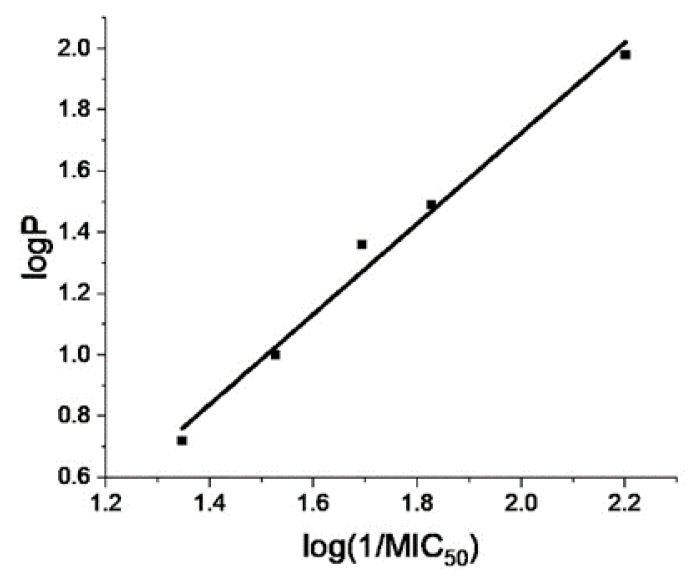

Figure 5. The $\log \mathrm{P}$ values of 2-PEtOH linearly correlate with the $\log \left(1 / \mathrm{MIC}_{50}\right)$ values. The $\log \mathrm{P}$ values of $2-\mathrm{PEtOH}$ and derivatives is plotted against the respective $\log \left(1 / \mathrm{MIC}_{50}\right)$ values. The correlation coefficient is $\mathrm{r}^{2}=0.987$.

In most cases, a clear effect on membrane lipid order was already observed in the liposome-based assay at the MIC50 values, and, thus, changes in general membrane properties could well have an important impact on the bacteriostatic activity of the 2$\mathrm{PEtOH}$ derivatives. Yet, there was no general correlation between the bacteriostaticity and the observed effect on the membrane structure: All substances clearly had an impact on bacterial growth, yet some substances increased the lipid order (phenylacetic acid, phenyllactic acid), Tyrosol did essentially not affect the membrane structure, whereas the remaining substances decreased the lipid order. Furthermore, it has to be noted that all molecules analyzed here might also have additional cellular targets.

In summary, our results indicate a correlation between the hydrophobicity of the 2-PEtOH derivatives analyzed here and their respective bacteriostatic activity, and our results link the biological activity of the molecules to cellular membranes.

Author Contributions: Conceptualization, N.H., E.T., T.B., and D.S.; methodology, I.S.K., S.P., A.C., and N.H.; software, A.C. and T.B.; validation, I.S.K., S.P., N.H., T.B., and D.S.; formal analysis, N.H., T.B., and D.S.; investigation, I.S.K., S.P., and A.C.; resources, T.B. and D.S.; writing-original draft preparation, I.S.K., T.B., and D.S.; writing-review and editing, N.H. and D.S.; visualization, I.S.K., T.B., and D.S.; supervision, T.B. and D.S.; project administration, T.B. and D.S.; funding acquisition, T.B. and D.S. All authors have read and agreed to the published version of the manuscript.

Funding: Isabel S. Kleinwächter, Nadja Hellmann, and Dirk Schneider were supported by DynaMem (state of Rhineland-Palatinate). Alessia Centi and Tristan Bereau acknowledge partial funding from the Emmy Noether Program of the Deutsche Forschungsgemeinschaft.

Institutional Review Board Statement: Not applicable.

Informed Consent Statement: Not applicable.

Data Availability Statement: All data is contained within this article. 
Acknowledgments: We thank Hildegard Pearson for critically reading the manuscript.

Conflicts of Interest: The authors declare no conflict of interest.

\section{References}

1. Ingram, L.O. Adaptation of membrane lipids to alcohols. J. Bacteriol. 1976, 125, 670-678. [CrossRef]

2. Ingram, L.O.; Vreeland, N.S. Differential effects of ethanol and hexanol on the Escherichia coli cell envelope. J. Bacteriol. 1980, 144, 481-488. [CrossRef] [PubMed]

3. Gutknecht, J.; Tosteson, D.C. Ionic permeability of thin lipid membranes: Effects of n-alkyl alcohols, polyvalent cations, and a secondary amine. J. Gen. Physiol. 1970, 55, 359-374. [CrossRef] [PubMed]

4. Silver, S.; Wendt, L. Mechanism of action of phenethyl alcohol: Breakdown of the cellular permeability barrier. J. Bacteriol. 1967, 93, 560-566. [CrossRef] [PubMed]

5. Zhu, Y.J.; Zhou, H.T.; Hu, Y.H.; Tang, J.Y.; Su, M.X.; Guo, Y.J.; Chen, Q.X.; Liu, B. Antityrosinase and antimicrobial activities of 2-phenylethanol, 2-phenylacetaldehyde and 2-phenylacetic acid. Food Chem. 2011, 124, 298-302. [CrossRef]

6. Lilley, B.D.; Brewer, J.H. The selective antibacterial action of phenylethyl alcohol. J. Am. Pharm. Assoc. Am. Pharm. Assoc. 1953, 42, 6-8. [CrossRef]

7. Anbazhagan, V.; Munz, C.; Tome, L.; Schneider, D. Fluidizing the Membrane by a Local Anesthetic: Phenylethanol Affects Membrane Protein Oligomerization. J. Mol. Biol. 2010, 404, 773-777. [CrossRef]

8. Stark, D.; Zala, D.; Münch, T.; Sonnleitner, B.; Marison, I.W.; Von Stockar, U. Inhibition aspects of the bioconversion of Lphenylalanine to 2-phenylethanol by Saccharomyces cerevisiae. Enzyme Microb. Technol. 2003, 32, 212-223. [CrossRef]

9. Brossmer, R.; Bohn, B.; Schlicker, H. Influence of 2-Phenylethanol and 1,1'Dimethylphenylethanol on metabolic activity and cell membrane function in ehrlich ascites tumor cells. FEBS Lett. 1973, 35, 191-194. [CrossRef]

10. Prevost, C.; Moses, V. Action of Phenethyl Alcohol on the Sythesis of Macromolecules in E. coli. J. Bacteriol. 1966, 91, 1446-1452. [CrossRef]

11. Masker, W.E.; Eberle, H. Effect of phenethyl alcohol on deoxyribonucleic acid-membrane association in Escherichia coli. J. Bacteriol. 1972, 109, 1170-1174. [CrossRef]

12. Lucchini, J.J.; Bonnaveiro, N.; Cremieux, A.; Le Goffic, F. Mechanism of bactericidal action of phenethyl alcohol in Escherichia coli. Curr. Microbiol. 1993, 27, 295-300. [CrossRef]

13. Lovrien, R.; Hart, G.; Anderson, K.J. Quantitative aspects of phenyl substituted alcohol and ether bacteriostatic interaction with Escherichia coli B/5. Microbios 1977, 20, 153-172. [PubMed]

14. Dieuleveux, V.; Lemarinier, S.; Guéguen, M. Antimicrobial spectrum and target site of D-3-phenyllactic acid. Int. J. Food Microbiol. 1998, 40, 177-183. [CrossRef]

15. Prema, P.; Smila, D.; Palavesam, A.; Immanuel, G. Production and characterization of an antifungal compound (3-phenyllactic acid) produced by Lactobacillus plantarum strain. Food Bioprocess. Technol. 2010, 3, 379-386. [CrossRef]

16. Lopez, S.; Bermudez, B.; Montserrat-De La Paz, S.; Jaramillo, S.; Varela, L.M.; Ortega-Gomez, A.; Abia, R.; Muriana, F.J.G. Membrane composition and dynamics: A target of bioactive virgin olive oil constituents. Biochim. Biophys. Acta Biomembr. 2014, 1838, 1638-1656. [CrossRef] [PubMed]

17. Sandler, M.; Ruthven, C.R.J.; Goodwin, B.L.; Lees, A.; Stern, G.M. Phenylacetic acid in human body fluids: High correlation between plasma and cerebrospinal fluid concentration values. J. Neurol. Neurosurg. Psychiatry 1982, 45, 366-368. [CrossRef]

18. Sherwin, C.; Kennard, K. Toxicity of phenylacetic acid. J. Inherit. Metab. Dis. 1919, 40, 259.

19. Hudgins, W.R.; Shack, S.; Myers, C.E.; Samid, D. Cytostatic activity of phenylacetate and derivatives against tumor cells. Biochem. Pharmacol. 1995, 50, 1273-1279. [CrossRef]

20. Mu, W.; Yu, S.; Zhu, L.; Zhang, T.; Jiang, B. Recent research on 3-phenyllactic acid, a broad-spectrum antimicrobial compound. Appl. Microbiol. Biotechnol. 2012, 95, 1155-1163. [CrossRef]

21. Dieuleveux, V.; Guéguen, M. Antimicrobial effects of D-3-phenyllactic acid on Listeria monocytogenes in TSB-YE medium, milk, and cheese. J. Food Prot. 1998, 61, 1281-1285. [CrossRef]

22. Mu, W.; Chen, C.; Li, X.; Zhang, T.; Jiang, B. Optimization of culture medium for the production of phenyllactic acid by Lactobacillus sp. SK007. Bioresour. Technol. 2009, 100, 1366-1370. [CrossRef]

23. Ning, Y.; Yan, A.; Yang, K.; Wang, Z.; Li, X.; Jia, Y. Antibacterial activity of phenyllactic acid against Listeria monocytogenes and Escherichia coli by dual mechanisms. Food Chem. 2017, 228, 533-540. [CrossRef]

24. Hillenga, D.J.; Versantvoort, H.J.M.; Van der Molen, S.; Driessen, A.J.M.; Konings, W.N. Penicillium chrysogenum takes up the penicillin $G$ precursor phenylacetic acid by passive diffusion. Appl. Environ. Microbiol. 1995, 61, 2589-2595. [CrossRef]

25. Bittenbender, W.A.; Bittenbender, E.F.D. The effect of para-substituents on the bacteriostatic properties of phenylacetic acid. J. Am. Pharm. Assoc. Am. Pharm. Assoc. 1972, 28, 514-519.

26. Giovannini, C.; Straface, E.; Modesti, D.; Coni, E.; Cantafora, A.; De Vincenzi, M.; Malorni, W.; Masella, R. Tyrosol, the Major Olive Oil Biophenol, Protects Against Oxidized-LDL-Induced Injury in Caco-2 Cells. J. Nutr. 1999, 129, 1269-1277. [CrossRef] [PubMed]

27. Covas, M.; Miró-Casas, E.; Fitó, M.; Farré-Albadalejo, M.; Gimeno, E.; Marrugat, J.; De LA Torre, R. Bioavalability of tyrosol, an antioxidant phenolic compound present in wine and olive oil, in humans. Drugs Exp. Clin. Res. 2003, 29, 203-206. [PubMed]

28. Fujita, T.; Winkler, D.A. Understanding the Roles of the "two QSARs". J. Chem. Inf. Model. 2016, 56, 269-274. [CrossRef] [PubMed] 
29. Parasassi, T.; De Stasio, G.; d’Ubaldo, A.; Gratton, E. Phase fluctuation in phospholipid membranes revealed by Laurdan fluorescence. Biophys. J. 1990, 57, 1179-1186. [CrossRef]

30. Nweke, C.O.; Ogbonna, C.J. Statistical models for biphasic dose-response relationships (hormesis) in toxicological studies. Ecotoxicol. Environ. Contam. 2017, 12, 39-55. [CrossRef]

31. Sezonov, G.; Joseleau-Petit, D.; D'Ari, R. Escherichia coli physiology in Luria-Bertani broth. J. Bacteriol. 2007, 189, 8746-8749. [CrossRef]

32. Gray, W.T.; Govers, S.K.; Xiang, Y.; Parry, B.R.; Campos, M.; Kim, S.; Jacobs-wagner, C. Nucleoid size scaling and intracellular organization of translation across bacteria. Cell 2019, 177, 1632-1648. [CrossRef]

33. Petrache, H.I.; Dodd, S.W.; Brown, M.F. Area per lipid and acyl length distributions in fluid phosphatidylcholines determined by 2H NMR spectroscopy. Biophys. J. 2000, 79, 3172-3192. [CrossRef]

34. Centi, A.; Dutta, A.; Parekh, S.H.; Bereau, T. Inserting Small Molecules across Membrane Mixtures: Insight from the Potential of Mean Force. Biophys. J. 2020, 118, 1321-1332. [CrossRef] [PubMed]

35. Hoffmann, C.; Centi, A.; Menichetti, R.; Bereau, T. Molecular dynamics trajectories for 630 coarse-grained drug-membrane permeations. Sci. Data 2020, 7, 1-7. [CrossRef] [PubMed]

36. Hess, B.; Kutzner, C.; Van Der Spoel, D.; Lindahl, E. GRGMACS 4: Algorithms for highly efficient, load-balanced, and scalable molecular simulation. J. Chem. Theory Comput. 2008, 4, 435-447. [CrossRef] [PubMed]

37. De Jong, D.H.; Singh, G.; Bennett, W.F.D.; Arnarez, C.; Wassenaar, T.A.; Schäfer, L.V.; Periole, X.; Tieleman, D.P.; Marrink, S.J. Improved parameters for the martini coarse-grained protein force field. J. Chem. Theory Comput. 2013, 9, 687-697. [CrossRef]

38. Bereau, T.; Kremer, K. Automated Parametrization of the Coarse-Grained Martini Force Field for Small Organic Molecules. J. Chem. Theory Comput. 2015, 11, 2783-2791. [CrossRef] [PubMed]

39. Sardessai, Y.; Bhosle, S. Tolerance of bacteria to organic solvents. Res. Microbiol. 2002, 153, 263-268. [CrossRef]

40. Bhal, S.; Log, P. Making Sense of the Value. Adv. Chem. Dev Inc. (ACD/Labs). Available online: https://www.google.com/url?sa= t\&rct=j\&q=\&esrc=s\&source=web\&cd=\&cad=rja\&uact=8\&ved=2ahUKEwjwpJ2c0tfvAhXzh_0HHahMA6AQFjABegQIBhAD\&

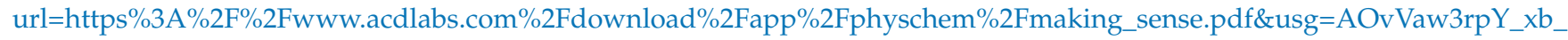
4mMyKpgWCWb3bm (accessed on 21 June 2018).

41. Paiva-Martins, F.; Gordon, M.H.; Gameiro, P. Activity and location of olive oil phenolic antioxidants in liposomes. Chem. Phys. Lipids 2003, 124, 23-36. [CrossRef]

42. Parasassi, T.; De Stasio, G.; Ravagnan, G.; Rusch, R.M.; Gratton, E. Quantitation of lipid phases in phospholipid vesicles by the generalized polarization of Laurdan fluorescence. Biophys. J. 1991, 60, 179-189. [CrossRef]

43. Parasassi, T.; Di Stefano, M.; Loiero, M.; Ravagnan, G.; Gratton, E. Influence of cholesterol on phospholipid bilayers phase domains as detected by Laurdan fluorescence. Biophys. J. 1994, 66, 120-132. [CrossRef]

44. Levison, M.E.; Levison, J.H. Pharmacokinetics and Pharmacodymanics of antibacterial agents. Infect. Dis. Clin. N. Am. 2009, 23. [CrossRef] [PubMed] 